\title{
Panel of Reviewers 2017
}

The editorial board of the Sri Lanka Journal of Surgery would like to greatly thank the panel of reviewers for their time andinvaluable assistance.

- Dr. Jayaindra Fernando, Consultant Surgeon, Lanka Hopsitals, Sri Lanka

- Dr. K Singapulli, Consultant Paediatric Cardiothoracic surgeon, Lady Ridgeway Hospital, Sri Lanka

- Prof. Nandadeva Samarasekera, Senior Professor and Chair of Surgery, Department of Surgery, Faculty of Medicine, University of Colombo, Sri Lanka

- Prof. Channa Ratnatunga, Emeritus Professor of Surgery and Honorary Consultant Surgeon, Department of Surgery, Faculty of Medicine, University of Peradeniya, Sri Lanka

- Prof Ranil Fernando, Head of the Department, cadre chair and Professor, Department of Surgery, Faculty of Medicine, University of Kelaniya, Sri Lanka

- Dr. T. Sabesan, Consultant Oral And Maxillofacial Surgeon, Colombo, Sri Lanka

- Dr. Asela Senanayake, Consultant Oncological Surgeon and Senior Lecturer in Surgery, Faculty of Medicine, Kotelawala Defence University, Sri Lanka

- Prof AH Sheriffdeen, Emeritus Professor of Surgery, Consultant General and Vascular Surgeon, Department of Surgery, Faculty of Medicine, University of Colombo, Sri Lanka

- Dr. Ranjuka Ubayasiri, Consultant vascular and transplant surgeon, Karapitiya, Teaching hospital, Karapitiya, Sri Lanka

- Mr. Michael Anthony Silva, Consultant Hepatobiliary and Pancreatic Surgeon, Oxford University Hospitals, NHS Foundation Trust, United Kingdom

- Dr. A. Surath D. Perera, Clinical Assistant Professor of Surgery, University of Tennessee, and Vascular Surgeon, Baptist Memorial Hospital, Memphis, Tennessee, United States of America.

- Dr. Satish Kumar Goonesinghe, Consultant Urological Surgeon, Karapitiya Teaching Hospital, Sri Lanka

- Dr. Kavinda Rajapakse, Consultant Plastic and Reconstructive Surgeon, Army Hospital, Colombo, Sri Lanka

- Prof. D.J. Anthony, Associate Professor in Anatomy and Consultant Surgeon, Faculty of Medicine, University of Colombo, Sri Lanka

- Dr. Udari Liyanage, Senior Lecturer in Anatomy and Consultant Radiologist, Faculty of Medicine, University of Colombo, Sri Lanka

- Dr. Ruwan Wijesuriya, Consultant General Surgeon, Perth, Australia

- Dr. Wasantha Wijenayake, Consultant Surgeon, Kothalawala Defence University, Sri Lanka

- Dr. Dammika Dissanayake Consultant Plastic Surgeon, National Hospital of Sri Lanka, Sri Lanka

- Dr Vihara Dassanayake, Senior Lecturer in Anaesthesiology and Consultant Anaesthetist, University Surgical Unit, Faculty of Medicine, University of Colombo, Sri Lanka

- Dr Rameendra Senaratne, Consultant General Surgeon, Army Hospital, Colombo, Sri Lanka 